\title{
Caesarean scar pregnancy: A rare form of ectopic pregnancy
}

\author{
Mily Pandey ${ }^{1}$, Monu Singh ${ }^{2, *}$, Achla Batra ${ }^{3}$, B. Preethi ${ }^{4}$, Inlo Miuli ${ }^{5}$ \\ ${ }^{1}$ Post Graduate Trainee, ${ }^{2,4}$ Senior Resident, ${ }^{3}$ Professor, ${ }^{5}$ Post Graduate Trainee, Dept. of Obstetrics and Gynecology, Safdarjung \\ Hospital, Delhi, India
}

*Corresponding Author:

Email: drmsingh1701@gmail.com

Received: $16^{\text {th }}$ May, 2018

Accepted: $12^{\text {th }}$ June, 2018

\begin{abstract}
Pregnancy in a caesarean scar is a rare entity where the pregnancy is implanted into a prior caesarean delivery uterine scar and located outside the normal uterine cavity. We report a case of caesarean scar ectopic pregnancy occurring in the scar of a previous caesarean section, diagnosed by ultrasonography and Doppler and the surgical management of such a case following failure of medical therapy. We present history, clinical findings and imaging of our case followed by discussion about, diagnosing and management of such a case and the options available.
\end{abstract}

Keywords: CSP - Caesarean scar pregnancy, LSCS- Lower segment caesarean section, POG - Period of gestation.

\section{Introduction}

Due to increasing number of caesarean delivery in the western world, there has been an associated increase in complications resulting in abnormal placentation and pregnancy implantation. ${ }^{1}$ Pregnancy developing within the fibrous tissue of a caesarean section scar is a rare entity. ${ }^{1}$ This condition can be life-threatening because of high risk of uterine rupture and massive uncontrolled haemorrhage. ${ }^{2}$ Recent data has shown an increasing trend towards caesarean section rates and hence increasing number of reported caesarean scar pregnancy. With high index of suspicion and liberal use of transvaginal sonography (TVS), the condition is being diagnosed early in pregnancy, further allowing for timely intervention and fertility preservation.

\section{Case Report}

A 32 year old, multi-gravidae G4P2L2A1 with previous two LSCS, presented in obstetrical emergency of Vardhaman Mahavir Medical College (VMMC) and Safdarjung Hospital (SJH) with pregnancy corresponding to 8 weeks 2 days POG with complaints of spotting per vagina since 1 day with a ultrasonography (USG) showing implantation in the previous caesarean scar. There was no history of passage of clots, fleshy mass or associated dizziness. In her history she further stated that following 8 weeks of amenorrhea and a positive urine pregnancy test (UPT) done at home, she underwent a routine $1^{\text {st }}$ trimester USG one week later. Her reports showed gestational sac corresponding to 6 weeks 4 days implanted in the region of previous scar with increased peritrophoblastic flow with foetal pole of $6 \mathrm{~mm}$ with presence of foetal cardiac activity. She had received one dose of injection methotrexate by a private practitioner outside following which her repeat USG showed presence of foetal cardiac activity in a $10 \mathrm{~mm}$ embryo implanted in the scar. On examination, there was no pallor with blood pressure $90 / 60 \mathrm{mmHg}$, heart rate - 120/min, with no orthostatic hypotension. Abdomen was soft, non-tense, non-tender with no guarding or rigidity. On speculum examination, old clotted blood was seen with no active bleeding. Laboratory investigations reported $\mathrm{Hb}-12.8 \mathrm{mg} / \mathrm{dl}, \mathrm{TLC}-7000 / \mathrm{mm}^{3}$, platelet count2.60L with liver function test, kidney function test and coagulation profile to be within normal limits. She was then taken for emergency laparotomy because of high chances of rupture of caesarean scar pregnancy. Intraoperatively, previous scar was found to be thinned out with only the serosal layer seen to be covering the fetal tissues implanted in the uterine scar, caesarean scar tissue with the gestation sac was removed. Uterus was closed in layers and foleys' catheter with bulb inflated to $5 \mathrm{cc}$ was left in situ so as to drain out any collections in the cavity. Foleys was removed 24 hour postoperatively. Her post op period was uneventful and patient was discharged on $4^{\text {th }}$ postoperative day. Histopathology report showed multiple grey brown soft tissue measuring $4 \times 3 \times 1 \mathrm{~cm}$ and section examined showed features of products of gestation.

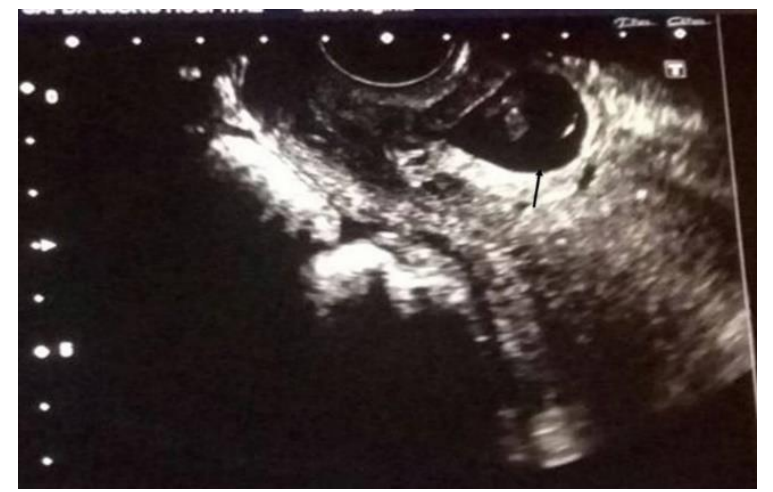

Fig. 1: TVS scan showing gestational sac implanted over previous scar (indicated by black arrow) 


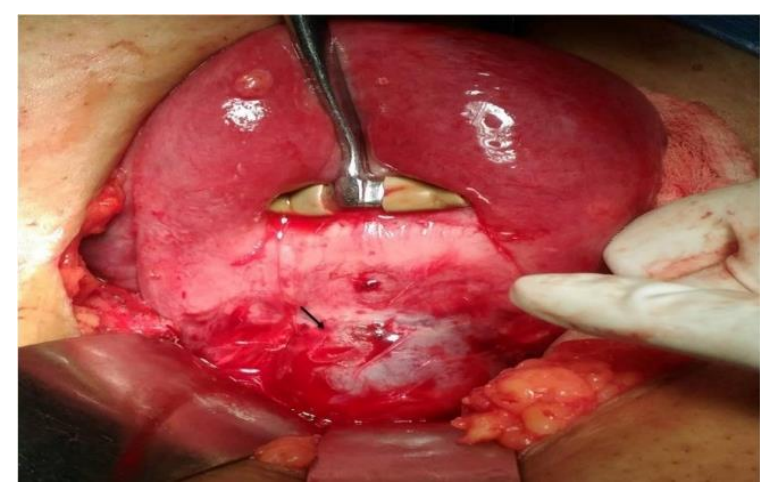

Fig. 2: Intra-op view of caesarean scar pregnancy

\section{Discussion}

The first case of a CS ectopic pregnancy was reported in the year $1978 .{ }^{2}$ Until the year 2001 only 19 such cases were reported. ${ }^{3}$ But over the recent years, there has been an increase in the number of Caesarean scar pregnancy cases, which may be due to rising rates of caesarean section, or due to better and early detection of the CSP by use of TVS ultrasound scan and other new imaging modalities. ${ }^{4,9}$ The various risk factors of caesarean scar ectopic include history of dilatation and curettage, placental pathology in previous pregnancy, manual removal of placenta, previous history of ectopic pregnancy, in vitro fertilization (IVF) conceived pregnancy, previous Caesarean sections, and history of prior uterine surgery such as myomectomy or metroplasty or therapeutic hysteroscopy. ${ }^{4}$ Caesarean scar pregnancy can be confused with an intrauterine pregnancy with placenta accreta. ${ }^{3}$ But in cases of placenta accreta there is absence of decidua basalis between the placenta and the endometrium and invasion of the myometrium by trophoblastic tissue and the pregnancy lies necessarily lies within the uterine cavity. Whereas in a cases of CSP, the gestation sac is completely surrounded by myometrium and the fibrous tissue of the scar, and the endometrial cavity is empty and the gestational sac lies outside uterine cavity. ${ }^{14}$ Histopathological findings have revealed that the villi are deeply penetrating the myometrium and are bound with it. ${ }^{17}$ Vial et al. ${ }^{18}$ proposed two different types of CSPs. The first is the cervicoisthmic type with implantation on the previous caesarean scar with progression towards the cervicoisthmic space, such variety of CSP may rarely progress to a viable birth but with a very high risk of life-threatening haemorrhage. The second variety is one which is deeply implanted into a previous scar growing towards the bladder and abdominal cavity, it is highly prone to rupture in early pregnancy. We encountered this variety of CSP in our case. A brief review regarding management of CSP has been described below.

\section{Diagnosis}

Ultrasound is the first-line, readily available and investigation of choice for diagnosing a CSP. CSPs can be diagnosed in early weeks by transvaginal scan (TVS). A sagittal view along the long axis of the uterus passing through the gestation sac has better chances of diagnosing a scar pregnancy. There are certain specified sonographic criteria for the diagnosis of a CSP which includes absence of fetal parts in the uterine cavity, presence of trophoblastic tissue between the bladder and the anterior uterine wall, absence of myometrium between the gestational sac and urinary bladder, no adnexal mass or free fluid in the pouch of douglas, unless the CSP has ruptured. ${ }^{3,15}$ A distinct circular peritrophoblastic perfusion surrounding the gestation sac can be seen on colour Doppler study, that can help delineate the CSP sac and its proximity to the bladder. The sac is well perfused in contrast to the avascular appearance of an aborting gestational sac. TV threedimensional (3-D) power Doppler ultrasound further enhances the diagnostic accuracy of CSP. Also Magnetic resonance imaging (MRI) can be used as an important diagnostic modality for providing detailed information about pregnancy implanted on a previous caesarean scar, which includes measuring volume of the lesion and hence predicting chances of successful methotrexate therapy and also has added advantage of improving intraoperative orientation. MRI is superior for assessment of pelvic structures as compared to USG. ${ }^{15}$ Diagnostic laparoscopy can also been used for diagnosis of scar pregnancy, findings include a normal sized or bulky uterus (depending on the gestation age) with the CSP, appearing as a bulge in the uterine serosa giving, 'a hillock with a salmon red appearance'.

\section{Treatment}

Treatment standards are lacking, but two main management options are available, the medical and surgical. Fertility preserving options include local or systemic methotrexate either alone or in combination with conservative surgery [uterus preserving surgery] in a hemodynamically stable patient. Previous case reports have suggested that it is better to consider systemic injection of methotrexate rather than local injection as local injections may disrupt the vascular supply of the ectopic gestation, leading to rupture of the caesarean scar pregnancy leading to bleeding and complications. ${ }^{3}$ Literature supports surgical treatment, even in the absence of active bleeding. ${ }^{16,17}$ This consists of planned elective laparotomy and excision of the gestational mass with the uterine scar. According to previously documented case reports resection of the old scar with 2 layer uterine closure can reduce the risk of recurrence. Also the follow-up period is much shorter compared with patients managed conservatively. Isthmic resection or resection of scar tissue with gestational sac with double layer closure can be performed laparoscopically, robotically or by open method. In most cases, uterus is preserved, although hysterectomy may have to be done in heavy uncontrolled bleeding. Often uterine artery embolisation is done post operatively to minimise 
hemorrhage risk. In our case, conservative surgical management was done after the failure of medical treatment, with all readiness for internal iliac ligation and hysterectomy.

\section{Conclusion}

Implantation of pregnancy in the scar of a previous caesarean section is one of the rarest form of ectopic pregnancy. It is a life threatening condition complicated with uterine rupture and torrential haemorrhage. Hence, early diagnosis of this condition using sonography combined with Doppler flow imaging is important, followed by confirmation by pelvic MRI if the diagnosis is in doubt. Treatment of this life threatening condition is also imperative. Although expectant management is also a treatment option but, mostly it is done surgically by resection of sac area and a two layer closure. Also hysterectomy can be done if the haemorrhage is uncontrolled. A surgeon competent to do internal iliac ligation and hysterectomy should only perform surgery for scar ectopic, as both may be required in extreme circumstances.

\section{References}

1. Fylstra DL, Pound-Chang T, Miller MG, Cooper A, Miller KM. Ectopic pregnancy within a cesarean delivery scar: a case report. Am Obstet GynecoI. 2002;187:302- 4.

2. Maymon R, Halperin R, Mendlovic S, Schneider O, Herman A. Ectopic pregnancies in a Cesarean scar: review of the medical approach to an iatrogenic complication. Hum Reprod. 2004;19:278-84.

3. Urkovic 0, Hillaby K, Woelfer B, Lawrence A, Salim R, Elson CJ. First-trimester diagnosis and management of pregnancies implanted into the lower uterine segment Cesarean section scar. Ultrasound Obstet GynecoI. 2003;21:220-7.

4. Larsen V, Solomon MH. Pregnancy in a uterine scar sacculus: an unusual cause of post-abortal haemorrhage. A case report. $S$ Afr Med. 1978;53:142-3.

5. Seow KM, Huang LW, Un YH, Un MY, Tsai YL, Hwang L. A Caesarean scar pregnancy: issues in management. Ultrasound Obstet Gynecol. 2004;23:247-53.
6. Graesslin 0, Dedecker F, Quereux C, Gabriel R. Conservative treatment of ectopic pregnancy in a Caesarean scar. Obstet GynecoI. 2005;105:869-71.

7. Marchiole P, Gorlero F, de Caro G, Podesta M, Valenzano M. Intramural pregnancy embedded in a previous caesarean section scar treated conservatively. Ultrasound Obstet Gynecol. 2004;23:307-9.

8. Godin P A, Bassil S, Donnez J. An ectopic pregnancy developing in a previous Caesarean section scar. Fertil Steril. 1997;67:398-400.

9. Seow KM, Cheng WC, Chuang J, Lee C, Tsai YL, Hwang L. Methotrexate for caesarean scar pregnancy after in vitro fertilization and embryo transfer. Reprod Med. 2000;45:754-7.

10. Fylstra DL. Ectopic pregnancy within a caesarean scar: a review. Obstet Gynecol Surv. 2002;57:537-43.

11. Vial Y, Petignat P, Hohlfeld P. Pregnancy in a caesarean scar. Ultrasound Obstet GynecoI. 2000;16:592-3.

12. Lai YM, Lee 0, Lee CL, Chen TC, Soong YK. An ectopic pregnancy embedded in the myometrium of a previous caesarean section scar. Acta Obstet Gynecol Scand. 1995;74:573-6.

13. Leeman LM, Wandland C. Cervical ectopic pregnancy. Diagnosis with endovaginal ultrasound examination and successful treatment with methotrexate. Arch Fam Med. 2000;9:72-7.

14. Yang M, Jeng MH. Combination of transarterial embolization of uterine arteries and conservative surgical treatment for pregnancy in a caesarean section scar. Reprod Med. 2003;48:213-6.

15. Lee CL, Wang CJ, Chao A, Yen CF, Soong YK. Laparoscopic management of an ectopic pregnancy in a previous caesarean section scar. Human Reprod. 1999;14:1234-6.

16. Ravhon A, Ben-Chetrit A, Rabinowitz R, Neuman M, Beller U. Successful methotrexate treatment of a viable pregnancy within a thin uterine scar. Br J Obstet Gynecol. 1997;104:628-29.

17. A. Rampen. An ectopic pregnancy embedded in the myometrium of a previous Caesarian section scar. Acta Obstet Gynecol Scand. 1997;76:492.

How to cite this article: Pandey M, Singh M, Batra A, Preethi B, Miuli I. Caesarean scar pregnancy: A rare form of ectopic pregnancy. Ind J Obstet Gynecol Res. 2018;5(3):433-435. 